\title{
Revisão de Literatura
}

\section{Redução da estigmatização e da discriminação das pessoas idosas com transtornos mentais: uma declaração técnica de consenso}

\section{Reducing stigma and discrimination against older people with mental disorders: a technical consensus statement}

Nori Graham ${ }^{1}$, James Lindesay ${ }^{2}$, Corneluus Katona ${ }^{3}$, José Manoel Bertolote ${ }^{4}$, Vincent Camus 5 , John R. M. Copeland ${ }^{6}$, Carlos

Augusto de Mendonça Lima ${ }^{5}$, Michel Gaillard ${ }^{5}$, Marie Christine Gély Nargeot ${ }^{7}$, John GraY ${ }^{8}$, Lars Jacobsson ${ }^{4}$, Mireille Kingma $^{9}$, Nicolas Kühne ${ }^{10}$, Anne O’Loughlin ${ }^{11}$, Wolfgang Rutz ${ }^{4}$, Benedetto Saraceno ${ }^{4}$, Zebulon Taintor ${ }^{12}$, Johannes Wancata ${ }^{13}$

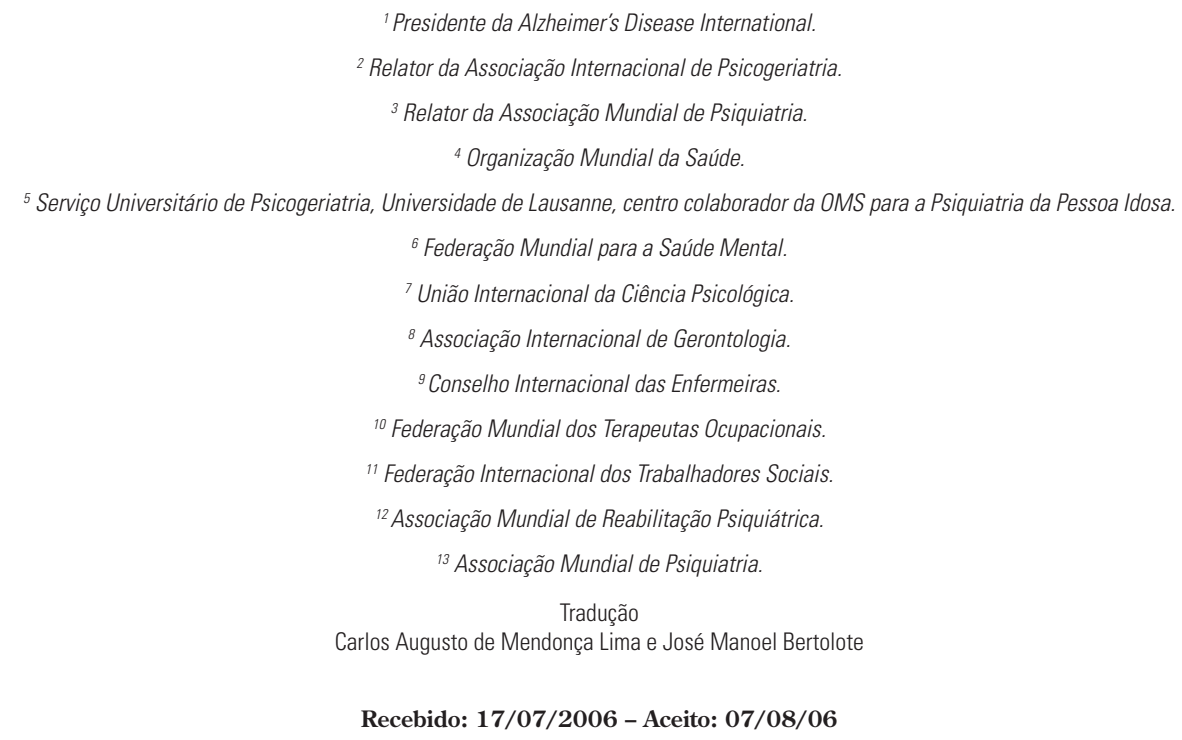

\section{Resumo}

A Organização Mundial da Saúde (OMS) e a Seção de Psiquiatria da Pessoa Idosa da Associação Mundial de Psiquiatria $(A M P)$, em colaboração com um grupo interdisciplinar de representantes das principais associações internacionais $e$ organizações não-governamentais implicadas na saúde mental das pessoas idosas, publicaram três declarações técnicas de consenso sobre a psiquiatria da pessoa idosa (1), a organização dos cuidados em psiquiatria da pessoa idosa (2) $e$ o ensino da psiquiatria da pessoa idosa (3). O Dia Mundial da Saúde 2001, cujo tema foi "Não à exclusão, sim aos cuidados", deu origem a uma nova reunião de consenso sobre o tema da estigmatização e discriminação das pessoas idosas com transtornos mentais. Essa nova reunião foi realizada em Lausanne nos dias 8 e 9 de outubro de 2001 e produziu uma declaração técnica de consenso. O texto inicial foi publicado pela OMS e AMP em inglês. Este artigo apresenta a versão em português desse documento.

Graham, N. et al. / Rev. Psiq. Clín. 34 (1); 39-49, 2007

Palavras-chave: Psiquiatria da pessoa idosa, psiquiatria geriátrica, psicogeriatria, estigmatização, discriminação, saúde mental, cuidados em saúde mental. 
Abstract

This technical consensus statement is jointly produced by the Old Age Psychiatry section of the World Psychiatric Association and the World Health Organization, with the collaboration of several NGOs and the participation of experts from different regions. It is intended to be a tool for (i) promoting debate at all levels on the stigmatization of older people with mental disorders; (ii) outlining the nature, causes and consequences of this stigmatization; and (iii) promoting and suggesting policies, programs and actions to combat this stigmatization.

Graham, N. et al. / Rev. Psiq. Clín. 34 (1); 39-49, 2007

Key-words: Old age psychiatry, psychogeriatrics, elderly people, stigma, discrimination, mental health, mental health care.

\section{Estigmatização, discriminação e transtornos mentais nas pessoas idosas}

A OMS e a AMP reconhecem que a estigmatização e a discriminação ligadas aos transtornos mentais estão fortemente associadas com o sofrimento, as incapacidades e as perdas econômicas. As recentes mudanças sociais, econômicas e demográficas constituem desafios importantes para as pessoas idosas e questionam o seu papel na sociedade. Além disso, as pessoas idosas que sofrem de transtorno mental são portadoras de um duplo fardo que justifica uma atenção particular. A presente declaração técnica de consenso (i) descreve a natureza, as causas e as consequiências dessa estigmatização e (ii) promove e propõe políticas, programas e ações para combatê-la.

Da mesma forma que nas precedentes declarações técnicas de consenso sobre a psiquiatria da pessoa idosa, a presente declaração foi produzida em colaboração multidisciplinar entre os representantes das seguintes organizações, todas implicadas neste campo, além da Associação Mundial de Psiquiatria e da Organização Mundial da Saúde: Alzheimer's Disease International, Associação Internacional de Gerontologia, Conselho Internacional das Enfermeiras, Federação Internacional dos Trabalhadores Sociais, Associação Internacional de Psicogeriatria, União Internacional da Ciência Psicológica, Associação Mundial de Reabilitação Psiquiátrica, Federação Mundial para a Saúde Mental e Federação Mundial dos Terapeutas Ocupacionais.

Agradecemos a todas essas organizações, e a seus representantes, que não economizaram tempo e contribuíram generosamente com suas idéias para produzir esta declaração de consenso. Nossa gratidão é também dirigida aos relatores, os Professores James Lindesay e Cornelius Katona, que reuniram todas as idéias apresentadas durante a reunião, assim como os comentários sugeridos durante $o$ extenso processo de consulta, e à Dra. Nori Graham, que conduziu as sessões da reunião com competência e diplomacia. Enfim, nosso reconhecimento também é dirigido ao Serviço Universitário de Psicogeriatria da Universidade de Lausanne e ao Dr. Carlos Augusto de Mendonça Lima, diretor do Centro Colaborador da OMS para a Pesquisa e o Ensino na Psiquiatria da Pessoa Idosa nesta universidade, por ter iniciado e organizado a reunião.

Estamos certos de que os leitores desta declaração achá-lá-ão útil para combater a estigmatização e a discriminação das pessoas idosas com transtornos mentais e para melhorar, assim, a qualidade de vida delas.

\section{Benedetto Saraceno Diretor do Departamento da Saúde Mental e Toxicomanias Organização Mundial da Saúde}

\section{Prefácio I}

Esta declaração de consenso é dedicada à memória do estimado Jean Wertheimer. Respeitando a tradição que ele estabeleceu como Presidente da Seção de Psiquiatria da Pessoa Idosa da Associação Mundial de Psiquiatria (AMP), os membros de seu serviço - os Drs. de Mendonça Lima, Gaillard e Camus - retomaram a tarefa de organizar uma reunião de consenso para produzir esta quarta declaração técnica de consenso. O grupo da reunião de consenso, formado pelos representantes de várias organizações, deve ser felicitado pela produção deste documento sucinto, relevante e prático.

A desestigmatização das pessoas idosas com transtornos mentais é prioritária no atual plano de ação da AMP. Sua Seção de Psiquiatria da Pessoa Idosa está orgulhosa de ser parceira na produção deste documento.

É desejável que esta declaração técnica de consenso contribua de modo significativo ao processo de desestigmatização, através de sua disseminação entre os profissio- 
nais, as autoridades governamentais, as ONGs, os corpos afiliados da OMS e as sociedades-membro da AMP.

Encorajamos todos aqueles que lerem esta declaração técnica de consenso a se engajar ativamente na redução da estigmatização e da discriminação das pessoas idosas com transtornos mentais na intenção de torná-las mais aptas a desfrutar uma melhor qualidade de vida.

Edmond Chiu, A.M. Presidente da Seção de Psiquiatria da Pessoa Idosa Associação Mundial de Psiquiatria

\section{Prefácio}

Esta quarta declaração técnica de consenso é uma contribuição ao Dia Mundial da Saúde 2001 e ao Relatório da Saúde no Mundo 2001. A OMS escolheu a Saúde Mental como tema para este dia pela segunda vez desde 1950. O slogan "Não à exclusão, sim aos cuidados" resume a principal mensagem que a OMS quis difundir no mundo todo: "Nada justifica colocar à margem da sociedade aqueles que sofrem de um transtorno mental ou cerebral".

Dra. Gro Harlem Brundtland, diretora-geral da OMS, que escreveu estas palavras no Relatório da Saúde no Mundo 2001, disse ainda: "Muitos de nós ainda nos afastamos assustados de tais pessoas ou fingimos ignorá-las - como se não nos atrevêssemos a compreender e a aceitar".

Como ela lembrou, 2001 foi também o décimo aniversário da adoção, em 1991, pela Assembléia Geral das Nações Unidas, da Declaração dos Direitos dos Doentes Mentais a uma Proteção e Cuidados. A seguir, alguns dos princípios enunciados por essa declaração:

- Nenhuma discriminação pode ser exercida sob o pretexto de uma doença mental;

- Cada doente mental tem o direito de ser cuidado na sua própria comunidade;

- Todo paciente tem o direito de ser colocado no meio o menos restritivo possível e aí receber o tratamento o menos constrangedor ou invasivo que lhe possa ser administrado.

$\mathrm{O}$ que dizer quanto ao respeito desses princípios em relação às pessoas idosas com transtornos mentais? Quando consideramos que 40\% dos países membros das Nações Unidas não têm uma política de saúde mental e que os cuidados para as pessoas idosas não são considerados uma prioridade na maior parte dos países do mundo, só podemos dar uma resposta pessimista a essa questão.

Os transtornos mentais nas pessoas idosas são freqüentes e representam um importante fardo para as sociedades.
Existe um risco elevado de que esse fardo aumente de modo dramático com o envelhecimento das populações. Neste contexto, a estigmatização é o obstáculo mais importante para assegurar o acesso aos cuidados de qualidade para as pessoas idosas com transtornos mentais.

O relatório do Cirurgião Geral dos Estados Unidos sobre a Saúde Mental, publicado em 1999, descreve do seguinte modo o impacto da estigmatização: "A estigmatização provoca a erosão da confiança de que os transtornos mentais sejam afecções que podem ser tratadas. Tem por consequiência limitar a socialização das pessoas com transtorno mental, em particular ao recusar-lhes oportunidades de emprego, de trabalho ou de moradia. A estigmatização dissuade o público a pagar pelos cuidados e, assim, reduz o acesso dos usuários aos recursos e às possibilidades de tratamento $\mathrm{e}$ de apoio social. A dificuldade ou a impossibilidade para obter um tratamento reforça as atitudes de diminuição da auto-estima, de isolamento e de desespero. A estigmatização despoja tragicamente a pessoa de sua dignidade e interfere em sua participação ativa na sociedade”.

Todas essas declarações são aplicáveis no contexto da psiquiatria da pessoa idosa. Isto explica por que os esforços conjuntos da OMS e da AMP para realizar as reuniões de consenso e as declarações técnicas de consenso são tão importantes. Tais declarações fornecem as bases para outros desenvolvimentos e constituem um material de referência importante para as autoridades governamentais, legisladores, associações de usuários, famílias e pacientes. Espera-se que essa declaração técnica de consenso possa contribuir para a redução do sofrimento das pessoas idosas com transtornos mentais em todo o mundo.

Carlos Augusto de Mendonça Lima Diretor do Centro Colaborador da OMS para a Psiquiatria da Pessoa Idosa - Universidade de Lausanne

\section{Redução da estigmatização e da discriminação das pessoas idosas com transtornos mentais}

\section{Uma declaração técnica de consenso}

A Organização Mundial da Saúde e a Associação Mundial de Psiquiatria já produziram três declarações técnicas de consenso no campo da psiquiatria da pessoa idosa (WHO/WPA, 1996; 1997; 1998). Tais declarações descrevem:

- a especialidade da psiquiatria da pessoa idosa;

- a organização dos serviços em psiquiatria da pessoa idosa; 
- o ensino e a formação em psiquiatria da pessoa idosa.

O objetivo desta quarta declaração técnica de consenso é colocar à disposição de todos um instrumento prático para ajudar na redução da estigmatização das pessoas idosas com transtornos mentais, mediante a:

- promoção do debate, em todos os níveis, sobre a estigmatização das pessoas idosas com transtornos mentais;

- descrição da natureza, das causas e das conseqüências dessa estigmatização;

- promoção e proposição de políticas, programas e ações para combater a estigmatização.

O público para quem esta declaração de consenso é destinada compreende os governantes, os profissionais, os membros das organizações não-governamentais (ONGs), a mídia, as famílias, os indivíduos acometidos por transtornos mentais, o público geral - toda pessoa que se encontre numa posição capaz de ajudar a reduzir a estigmatização e a discriminação das pessoas idosas com transtornos mentais.

\section{Definições}

O estigma resulta de um processo por meio do qual certas pessoas e grupos de pessoas são levados a se sentir envergonhados, excluídos e discriminados.

A discriminação refere-se a toda distinção, exclusão ou preferência que tem como efeito a abolição ou diminuição do gozo equitativo de direitos. As medidas especiais para proteger os direitos das pessoas com transtornos mentais ou para assegurar seu futuro não deveriam ser discriminatórias. A discriminação não inclui toda distinção, exclusão ou preferência necessárias para a proteção de direitos de uma pessoa com ou sem transtorno mental.

Os transtornos mentais são problemas de saúde classificados pela CID-10 da OMS no capítulo V - "Transtornos mentais e do comportamento" (WHO, 1992).

A pessoa idosa é definida neste documento como aquela que tem mais de 65 anos. No entanto, a percepção de um indivíduo como idoso varia segundo as culturas.

\section{Princípios gerais}

Toda pessoa com transtorno mental (ou que tenha sido tratada como tal) deve ser tratada com humanidade e respeito que lhe são devidos pelo princípio de respeito da dignidade humana (United Nations, 1995). Em conseqüência, a estigmatização das pessoas idosas com transtorno mental (alguma vezes chamada de estigmatização psiquiátrica) deve ser combatida em toda parte e sempre. No entanto, a estigmatização é uma característica frequiente no ser humano, sendo invasora, sutil e difícil de combatê-la na ausência de estratégias claras e elaboradas.

Até o presente momento, a maior parte da atenção foi dispensada ao problema da estigmatização das pessoas mais jovens com transtornos mentais (Hayward e Bright, 1997; Sartorius, 1999; Corrigan e Watson, 2002). A finalidade desta declaração de consenso é focalizar tal atenção nas pessoas idosas. Como a estigmatização na idade avançada - independentemente da estigmatização ligada à doença mental - está igualmente presente na maior parte das sociedades (mas não em todas), há, então, um duplo prejuízo para as pessoas idosas com transtornos mentais, e ambos deveriam ser levados em conta no contexto das estratégias antiestigmatização.

- Essa estigmatização é inaceitável, e toda pessoa idosa tem o direito de ser protegida dela.

- Combater a estigmatização e a discriminação é um dever dos governantes, das organizações não-governamentais, dos serviços, das associações de pacientes, das famílias e do público em geral. Para serem eficazes, todos esses grupos deveriam trabalhar em parceria.

- As ações contra a estigmatização e a discriminação das pessoas idosas com transtornos mentais deveriam:

- ser uma prioridade de todos para atingir o estado de bem-estar físico, mental e social definido pela Constituição da OMS (WHO, 2001);

- fazer parte da promoção de uma boa saúde mental, mediante a formação de profissionais e educação do público;

- ser uma finalidade maior dos programas em todos os níveis do domínio da saúde e do social.

\section{As causas e as conseqüências da estigmatização e da discriminação das pessoas idosas com transtornos mentais}

As causas

A estigmatização tem componentes cognitivos e comportamentais e ambos devem ser alvos de ações específicas para sua redução. O estigma é o resultado de um processo cognitivo normal de avaliação de ameaças e riscos que organiza os conhecimentos sociais e deter- 
mina as autopercepções. No caso das pessoas idosas com transtornos mentais, resulta:

- da ignorância e de idéias preconcebidas relativas à natureza da idade avançada, dos transtornos mentais e de seu tratamento;

- do medo dos danos, da contaminação, do desconhecido, do fardo dos cuidados, de seu próprio envelhecimento;

- da tendência à conformidade social e à segurança e, por consequiência, da supressão dos comportamentos desviantes e das diferenças;

- da acentuação das idéias estigmatizantes pelas suas vítimas.

A estigmatização das pessoas idosas com transtornos mentais pode ser reforçada por:

- fatores culturais, tais como as diferenças em crenças específicas e no que diz respeito ao valor das pessoas mais idosas na sociedade, da origem dos transtornos mentais e no que isso implica para a família e o doente;

- a instabilidade socioeconômica e as crises: as guerras, as migrações, a chegada de refugiados etc. encorajam a estigmatização das pessoas com transtornos mentais de todas as idades;

- a ausência ou a inadequação, real ou ressentida, das estratégias preventivas ou de tratamento dos transtornos mentais;

- falta de sistemas de informação para formar profissionais e o público em geral;

- discriminação sexual, que pode ser agravada na idade avançada, quando o número de mulheres ultrapassa o de homens (neste casos, existe um triplo prejuízo para as mulheres idosas com transtornos mentais);

- toda forma de recompensa para aqueles que estigmatizam: financeira, negação dos problemas, reforçamento do status social, aumento da auto-estima.

\section{As conseqüências}

A estigmatização das pessoas idosas com transtornos mentais pode provocar o desenvolvimento de atitudes negativas, tais como:

- preconceitos: por exemplo, a idéia de que as pessoas com transtornos mentais são perigosas, fracas, irresponsáveis etc.;

- preconceitos populares que dizem que as pessoas idosas são fracas, doentes, bizarras, intransigentes, inúteis etc.;
- convicções falsas sobre a responsabilidade individual quanto a doença mental e suas conseqüências;

- criação de estereótipos populares tanto sobre as pessoas idosas quanto sobre as pessoas com transtornos mentais, às vezes retomados pela mídia;

- convicções que causam danos sustentadas pelos que são estigmatizados (ou que poderiam sê-lo), como a vergonha, a baixa auto-estima, a falta de vontade para abordar os problemas ou fazer uso dos serviços de apoio;

- criação de assuntos tabus e a falta de debate público;

- atitudes negativas dos profissionais contra as pessoas idosas com transtornos mentais;

- atitudes negativas contra os profissionais que cuidam das pessoas idosas com transtornos mentais;

- opiniões alarmistas dos profissionais e do público em geral sobre as necessidades, o fardo e o custo dos cuidados.

Essas atitudes negativas podem se tornar discriminatórias contra as pessoas idosas com transtornos mentais:

Em relação a:

- indivíduos;

- suas famílias;

- aqueles que dispensam cuidados (famílias, profissionais, serviços etc.).

Onde:

- em casa;

- no trabalho;

- na comunidade;

- nos serviços sociais e sanitários;

- no âmbito da pesquisa médica;

- no âmbito da justiça;

- nos serviços financeiros;

- no âmbito dos serviços de segurança (polícia);

- na mídia.

Em termos de:

- má qualidade dos tratamentos e dos cuidados (do acesso aos cuidados, dos cuidados fornecidos, dos resultados obtidos, as recaídas);

- marginalização dos pacientes no interior dos sistemas de cuidados;

- exclusão do sistema de cuidados;

- baixo prestígio dos profissionais e dos serviços de cuidados;

- recrutamento de pessoal profissional pouco ou mal formado; 
- financiamento inadequado do sistema de saúde nos âmbitos local e nacional;

- desigualdade no reembolso dos tratamentos;

- impacto negativo nas famílias (vergonha, impossibilidade de se casar ou de criar uma relação afetiva, perda dos amigos);

- violência, abuso, maus-tratos;

- institucionalização evitável;

- atitudes de evitação: afastamento, exclusão social das vítimas e falta de reconhecimento quanto a suas vivências;

- má qualidade de vida;

- exclusão da pesquisa e, em consequiência, falta de evidências científicas para informar os que possuem poder de decidir;

- efeitos econômicos desfavoráveis (pessoal e social);

- legislação discriminatória;

- desemprego, nas sociedades em que as pessoas idosas permanecem no mercado de trabalho;

- desigualdade material e financeira (isto é, no acesso aos recursos básicos, aos seguros e às hipotecas);

- negligência da parte dos governantes e ausência de proteção legal;

- utilização de linguajar pejorativo (exemplo: "velho" etc.).

Existem várias interações nefastas entre as atitudes estigmatizantes relativas às doenças mentais e à idade avançada. Por exemplo:

- a suposição de que as pessoas idosas são rígidas, inflexíveis e incapazes de mudar, o que reforça a idéia popular de que os transtornos mentais na idade avançada são incuráveis.

- o efeito negativo da presença de antecedentes psiquiátricos no acesso aos cuidados somáticos para as pessoas idosas.

- o efeito negativo dos transtornos mentais das pessoas idosas nas atitudes dos seus meios familiar e profissional quanto a sua autonomia e sua capacidade de tomar decisões.

- a banalização pelos próximos das queixas das pessoas idosas.

- a falta de interesse de vários profissionais e serviços pelas suas próprias pessoas idosas com transtornos mentais crônicos.

- o fato de que a psiquiatria e os serviços de psiquiatria sejam considerados pelas pessoas idosas como estigmatizantes e, em conseqüência, de pouca utilidade para elas.

- o fato de os critérios diagnósticos não levarem suficientemente em conta as especificidades ligadas à idade avançada.

\section{A estigmatização em certos transtornos mentais na idade avançada}

Este capítulo descreve como certos transtornos mentais da idade avançada são estigmatizantes.

\section{Depressão}

- A depressão é freqüentemente considerada pelos pacientes, suas famílias e mesmo por certos profissionais como uma consequiência natural do processo de envelhecimento, das perdas que as pessoas idosas sofrem, dos problemas somáticos que as afetam ou mesmo como sinal de fraqueza pessoal. Certos sintomas (estados de cansaço, retraimento social) são particularmente mal interpretados.

- Certas formas de tratamento, que são percebidas como mais estigmatizantes (ECT, psicotrópicos) que outras (psicoterapias), são mais facilmente oferecidas às pessoas idosas.

- Os componentes cognitivos da depressão (culpa, pessimismo, desespero etc.) e comportamentais (tentativa de suicídio) têm um impacto estigmatizante nas vítimas e nas suas famílias.

- A depressão e a ansiedade são percebidas pelo meio e pelos pacientes como marcas de fraqueza pessoal.

Demência

- A demência é frequientemente percebida como parte do processo natural do envelhecimento, o que impede seu reconhecimento e o tratamento apropriado do paciente.

- No entanto, certos sintomas das demências são muito estigmatizantes (transtornos do comportamento, maus cuidados pessoais, incontinência) tanto no contexto da comunidade quanto nos serviços. Em certas culturas, esses sintomas podem ser considerados como maus-tratos prodigados pelas famílias, que podem ser penalizadas em conseqüência. 
- A utilização popular (e, às vezes, também pelos profissionais) do termo "demência" ou "demente" tem com frequiência conotação estigmatizante.

- A pessoa idosa com perda de memória perde lembranças de seu passado, o que explica a conversão, pela sociedade, de seu status de sujeito ao de objeto. Resulta disso um esquecimento de suas crenças culturais e religiosas, assim como de seus desejos pessoais.

- As pessoas idosas que sofrem de demência são percebidas como não tendo mais uma boa qualidade de vida, nem capacidade para ter prazer.

- O diagnóstico de demência pode levar a excluir esses doentes de certos tipos de tratamento (reanimação cardiovascular, hospitalizações, longas estadas em instituições), tanto nos países desenvolvidos quanto nos países em desenvolvimento.

Por outro lado, em certas culturas, o fato de que as demências sejam de etiologia orgânica permite reduzir o risco de estigmatização, pois certos pacientes não são percebidos como portadores de "doença mental". Isto é o reflexo da ambigüidade da classificação desse transtorno e pode ter conseqüências em termos de organização de cuidados e de cobertura pelas empresas de seguro-saúde.

\section{Transtornos confusionais agudos (delirium)}

- Nas pessoas idosas, este problema é muitas vezes provocado pelas doenças somáticas ou por consumo abusivo de medicamentos prescritos. $\mathrm{O}$ tratamento frequientemente inapropriado do transtorno confusional nos pacientes hospitalizados mostra que, num serviço de cuidados para problemas somáticos, os transtornos mentais são com freqüência estigmatizados. A conseqüência é o não-reconhecimento do problema, a ausência de diagnóstico correto e a falta de proposta terapêutica válida. A freqüente percepção falsa de que a confusão é sempre um problema "barulhento" implica que os episódios menos evidentes nas pessoas idosas são muitas vezes não reconhecidos.

\section{Psicoses}

- O efeito estigmatizante das psicoses foi bem descrito nos jovens adultos. O diagnóstico de esquizofrenia é menos utilizado em psiquiatria da pessoa idosa, mas quando o é, o mesmo estigma se encontra presente.

- As pessoas idosas com transtornos psicóticos são percebidas como menos perigosas que as pessoas mais jovens com o mesmo diagnóstico (e elas são, então, menos estigmatizadas que estas).

- No entanto, o preconceito acerca de que as pessoas idosas são todas bizarras faz que os transtornos psicóticos sejam menos identificados e as pessoas portadoras não sejam reconhecidas nas suas dificuldades, nem lhe sejam propostos os tratamentos e as abordagens de reabilitação que lhes são necessários.

Ansiedade

- Existe uma forma de estigmatização que consiste em considerar todas as pessoas idosas como medrosas, o que torna difícil o reconhecimento dos transtornos ansiosos.

- Em relação às manifestações do estresse póstraumático, as consequiências tardias dos traumatismos antigos não são freqüientemente reconhecidas, prova suplementar do não-reconhecimento da história do paciente.

\section{Abuso de substâncias (álcool e medicamentos)}

- O abuso de substâncias é com freqüência subdiagnosticado nas pessoas idosas, sobretudo por causa do preconceito de que esse problema só ocorre na idade adulta.

- Há um pessimismo terapêutico inadequado quanto a esse problema nas pessoas idosas.

- Os serviços especializados para o tratamento desse tipo de problema utilizam um limite de idade além do qual os pacientes são recusados.

\section{Transtornos de personalidade}

- Os transtornos de personalidade não são frequientemente diagnosticados por causa de preconceitos, que dizem que as pessoas idosas são todas especiais.

- As pessoas idosas com transtornos de personalidade são com frequiência excluídas de toda forma de cuidados de que necessitam. 


\section{Transtornos de aprendizagem}

- Os serviços sociais são freqüentemente mal equipados para cuidar de pessoas idosas com transtornos de aprendizado.

- As pessoas idosas com transtornos de aprendizado são freqüentemente excluídas dos cuidados quando desenvolvem outros transtornos mentais.

\section{Ações contra a estigmatização e a discriminação}

Uma abordagem estratégica

Eliminar ou reduzir a estigmatização implica, sobretudo, adotar medidas de ensino para mudar crenças e atitudes, enquanto para mudar a discriminação necessita-se de ações no âmbito das leis e da justiça. Os principais objetivos de uma estratégia para reduzir a estigmatização e a discriminação no contexto da idade avançada são:

- assegurar que os sistemas sociais e sanitários apropriados estejam funcionando e que respondam às necessidades das pessoas idosas com transtornos mentais, assim como de seus próximos;

- incluir a saúde mental das pessoas idosas na planificação da ação pública. Os transtornos mentais são tão importantes na idade avançada quanto nos outros períodos da vida (o que implica também encorajar a promoção de noções positivas relativas ao envelhecimento);

- promover maior aceitação pela sociedade das pessoas idosas com transtornos mentais;

- criar ambientes mais adaptados para as pessoas idosas com transtornos mentais;

- encorajar a pesquisa para os tratamentos eficazes e cuidados não-estigmatizantes para as pessoas idosas com transtornos mentais.

Atingir esses objetivos implica:

- rever nossas atitudes e práticas;

- aumentar o conhecimento;

- apoiar a responsabilização das pessoas;

- evitar a exclusão;

- assegurar os tratamentos e os cuidados adequados;

- favorecer as manifestações críveis de defesa de interesses;

- desenvolver programas de informação e de formação para o público e os profissionais;

- distribuir de forma igualitária os recursos orçamentários para a saúde, o social e a pesquisa;
- prever a inclusão das mudanças demográficas nacionais no estabelecimento da planificação oficial.

Se os governos têm responsabilidade primária na redução da estigmatização e da discriminação, outros indivíduos também têm papel importante a desempenhar nesse campo. Uma lista de papéis, responsabilidades e oportunidades de um conjunto de grupos de pessoas encontra-se descrita a seguir. Não é exaustiva nem exclusiva. Deve ser considerada como uma lista de sugestões para ações diretas ou ações de pressão. Essa lista fornece uma base para o desenvolvimento de um plano de ações no âmbito local. Esse tipo de plano deve incluir a colaboração entre vários setores, se possível sob a direção de uma organização governamental e/ou de profissionais, e deve ser realista, executável, limitado no tempo e, se possível, avaliado.

Também é útil para os projetos de ação no âmbito local dispor de mensagens impactantes. Aqui constam alguns exemplos dessas mensagens:

- A maior parte das pessoas idosas se encontra em bom estado de saúde.

- Os transtornos mentais na idade avançada são tratáveis.

- A depressão é uma doença que pode ser cuidada, e não uma fraqueza do espírito.

- Toda pessoa que sofre de demência pode ter uma boa qualidade de vida.

- Se você se sente cansado ou tem esquecimentos freqüentes, procure o seu médico.

- A estigmatização é prejudicial.

- Estigmatização e discriminação ferem - combata-as.

- Todos podem ser vítimas de discriminação.

Papéis, responsabilidades e oportunidades

Legisladores, governos (âmbitos nacional e local):

- Os serviços sociais e de cuidados para as pessoas idosas devem ser planificados, financiados e prestados no contexto do sistema social e de cuidados geral, segundo as orientações fixadas nas precedentes declarações técnicas de consenso da OMS/AMP (WHO, WPA, 1996; 1997; 1998). Para isto, é necessário:

- equipe adequadamente formada;

- um ambiente de trabalho seguro; 
- sistemas confiáveis de informação para as necessidades de avaliação e para assegurar prestações de qualidade;

- desenvolvimento de serviços distintos para as pessoas idosas com necessidades secundárias;

- vantagens financeiras para os profissionais responsáveis por cuidados primários para efetuar avaliações regulares das pessoas idosas.

- Políticas e leis específicas relativas à estigmatização e à discriminação desenvolvidas em todos os âmbitos do governo.

- Temas relativos à saúde mental devem estar presentes em todas as agendas dos partidos políticos.

- Recursos necessários devem ser alocados para o desenvolvimento e a realização de campanhas de informação e de ensino utilizando a mídia. Os governos devem particularmente assegurar que temas sobre os transtornos mentais nas pessoas idosas sejam incluídos nos programas das escolas.

- Os responsáveis políticos devem ainda assegurar que os profissionais, os membros das famílias e os pacientes possam se exprimir - e que eles sejam ouvidos.

- As justiças nacional e local devem fornecer proteção efetiva e acessível contra a estigmatização e a discriminação.

- Os serviços devem ser planificados para assegurar acesso igualitário e ajuda para as pessoas idosas com transtornos mentais. Isto inclui:

- pensões e aposentadoria adequadas;

- uma gama de serviços comunitários e de atividades orientadas para o grupo de pessoas idosas; - serviços de transporte público adaptados às pessoas idosas.

- Promoção de oportunidades para a pesquisa médica e em ciências sociais no domínio da saúde mental em pessoas idosas para assegurar o aumento do nível dos conhecimentos e encorajar as práticas baseadas em evidências.

As organizações não-governamentais (ONGs) têm papel determinante:

- no desenvolvimento de políticas apropriadas e relevantes no seu setor de influência;

- no desenvolvimento da tomada de consciência da denúncia de problemas;

- na coordenação da colaboração em rede dos diversos parceiros;
- na criação de oportunidades para que as pessoas idosas com transtornos mentais e seus cuidadores possam se expressar em público;

- na seleção e apoio das personalidades reconhecidas como porta-voz;

- no desenvolvimento e manutenção:

- das campanhas de informação;

- dos serviços de aconselhamento;

- dos websites;

- dos documentos adaptados;

- dos vínculos educativos com as escolas $\mathrm{e}$ universidades.

- no estabelecimento de vínculos com os jornalistas;

- na produção de informação para a mídia;

- no estabelecimento dos contatos diretos face a face;

- na criação de seminários para os jornalistas e que eles sejam implicados nas suas atividades;

- na supervisão do material divulgado pela mídia (fazendo comentários sobre as matérias inadequadas);

- no exemplo que dão por meio da utilização de políticas de cuidados de apoio.

Os profissionais deveriam:

- assegurar-se, antes de mais nada, de que sua prática é livre de toda forma de estigmatização e discriminação;

- associar-se às autoridades políticas, às ONGs, aos pacientes e às suas famílias, a fim de planificar e desenvolver serviços e assegurar que estes evitem estigmatizar e discriminar;

- assegurar-se de que todos os currículos de ensino e de formação contínua prevejam:

- material apropriado sobre os transtornos mentais na idade avançada;

- material de formação para desenvolver o saber sobre a estigmatização e a discriminação;

- formação para assegurar que as prestações de cuidados planificadas levem em conta de modo positivo os aspectos ligados à saúde mental e ao envelhecimento;

- uma supervisão contínua.

- assegurar-se de que os assuntos relativos aos transtornos mentais nas pessoas idosas recebam suficientemente atenção dos pesquisadores;

- assegurar-se de que as instâncias profissionais tenham políticas para identificar e reduzir a estigmatização e a discriminação; 
- assegurar-se de que as políticas relativas ao trabalho prevejam a identificação e a redução da estigmatização e da discriminação;

- fornecer informação e consultoria para os cuidadores e famílias dos pacientes sobre:

- as doenças;

- os tratamentos;

- os serviços comunitários e especializados;

- o trabalho das ONGs mais úteis.

- ajudar os pacientes, suas famílias e os demais profissionais do domínio dos cuidados a gerir as situações de estigmatização e de discriminação que eles encontram;

- fornecer informações precisas para os jornalistas;

- disseminar informação sobre as boas práticas baseadas em evidências para assegurar o tratamento precoce e eficaz dos transtornos mentais nas pessoas idosas;

- assegurar e validar o nível de competência dos cuidadores.

Os cuidadores e as famílias podem se tornar mais eficazes quando:

- participam ou formam associações e grupos de apoio;

- fornecem informações sobre suas necessidades e vivências aos prestadores de cuidados, ONGs e governos;

- informam as autoridades competentes sobre suas experiências concretas, suas dificuldades em relação às doenças mentais e às situações de discriminação e sobre as soluções encontradas;

- aumentam os contatos com os membros da comunidade local;

- participam da planificação dos serviços para prevenir o estigma e a discriminação;

- utilizam seu papel de consumidores preferindo os serviços que combatem a estigmatização e a discriminação;

- reivindicam as medidas contra a estigmatização e a discriminação;

- denunciam as situações de discriminação que constatam.

As pessoas idosas com transtornos mentais deveriam ser encorajadas a:

- tornar públicas suas experiências relativas à idade avançada, à doença e aos eventuais atos de discriminação de que tenham sido vítimas;

- participar de campanhas de informação e de ensino;
- juntar-se às associações e aos grupos de apoio;

- expressar suas necessidades àqueles que dispensam cuidados, às ONGs e às autoridades governamentais;

- colaborar na planificação dos serviços, a fim de que estes evitem estigmatizar e discriminar;

- denunciar toda prática profissional que seja estigmatizante e discriminatória.

A população geral poderia:

- exercer uma influência construtiva sobre as autoridades políticas e institucionais;

- pressionar para que serviços adequados em prol das pessoas idosas com transtornos mentais sejam criados e que estes respeitam os direitos do cidadão.

A mídia deveria:

- estabelecer políticas que evitem a disseminação de material estigmatizante e discriminatório;

- reconhecer o potencial para criar ou sustentar mitos sobre os transtornos mentais nas pessoas idosas -e tomar as medidas necessárias para evitá-las;

- reconhecer sua responsabilidade para promover a verdade sobre os transtornos mentais na idade avançada;

- assegurar que os jornalistas sejam bem informados sobre os transtornos mentais na idade avançada;

- aproveitar cada ocasião para citar:

- informações apropriadas sobre os transtornos mentais na idade avançada;

- as más assim como as boas práticas e toda forma de abuso;

- os efeitos negativos do estigma e da discriminação;

- histórias positivas sobre pessoas idosas com transtornos mentais.

- evidenciar a necessidade por serviços;

- fornecer à população informações sobre serviços, grupos de apoio e associações existentes.

As empresas deveriam:

- assegurar que exista uma política antidiscriminatória (seguro social, apoio aos trabalhadores no local de trabalho, condições de aposentadoria);

- apoiar financeiramente campanhas educativas e na mídia;

- ser sensíveis às necessidades de seus empregados idosos, bem como às daqueles que se ocupam dessas pessoas; 
- assegurar que seus empregados tenham acesso aos meios para assumir as prestações de cuidados para si mesmos e para seus pais;

- assegurar que as pessoas idosas - assim como as pessoas que têm transtornos mentais - tenham o acesso facilitado aos produtos da empresa e aos serviços que esta dispensa.

As escolas, as universidades e os demais centros de formação profissional deveriam:

- criar oportunidades de contato entre as gerações;

- incluir aspectos da saúde mental e do envelhecimento em seus programas de ensino.

\section{Conclusão}

A estigmatização e a discriminação contra as pessoas idosas com transtornos mentais são muito difundidas e suas conseqüências, muito importantes. É imperativamente fundamental a condução de pesquisas para identificar essa estigmatização e essa discriminação, a fim de definir o contexto em que se manifestam e medir seus efeitos. É igualmente importante promover a pesquisa para identificar os meios de intervenção para reduzir de modo durável as formas de estigmatização e discriminação.

Esta declaração de consenso tenta resumir algumas evidências disponíveis atualmente e propor práticas para ações concretas. O desenvolvimento de serviços de cuidados para as pessoas idosas com transtornos mentais deve ser a principal medida a se tomar em toda estratégia para reduzir a estigmatização e a discriminação. Ações necessitam ser desenvolvidas em âmbito local para assegurar que sejam bastante sensíveis e suficientemente específicas em relação às necessidades e à cultura local.

Seminários e outras reuniões que utilizem esta declaração de consenso como ponto de partida, englobando vários organismos e associações, podem ser úteis para o desenvolvimento de planos de ação apropriados em âmbito local ou nacional.

\section{Referências}

Corrigan, P.W., Watson, A.C. Understanding the impact of stigma on people with mental illness. World Psychiatry 1: 16-19, 2002: and subsequent commentaries.

Hayward, P., Bright, J.A. Stigma and mental illness: a review and critique. Journal of Mental Health 6: 345-354, 1997.

Sartorius, N. On of the last obstacles to better mental health care: the stigma of mental illness. In: Guímon, J., Fischer, W., Sartorius, N. (eds.). The image of madness. The public facing mental illness and psychiatric treatment. Karger, Basel, pp. 96-104, 1999.

United Nations. Principles for the protection of persons with mental illness and for the improvement of mental health care. Adopted by the United Nations General Assembly Resolution 46/119 of December 1991.

WHO. The ICD-10. International Statistical Classification of Diseases and Related Health Problems. Tenth Revision. WHO, Geneva, 1992.

WHO. Constitution of the World Health Organization. Basic Documents. WHO, Geneva, 2001. pp. 1-18.

WHO/WPA. Psychiatry of the elderly. a consensus statement. WHO, Geneva, 1996. WHO/MNH/MND/96.7.

WHO/WPA. Organization of care in psychiatry of the elderly. a technical consensus statement. WHO, Geneva, 1997. WHO/MSA/MNH/MND/97.3.

WHO/WPA. Education in psychiatry of the elderly. a technical consensus statement. WHO, Geneva, 1998. WHO/MNH/MND/98.4 